\title{
Are we Accidentally Paying Donors to Donate?: There's an Easy way to Stop these Unintentional Violations of Nota
}

\author{
Sigrid Fry-Revere* \\ Georgetown University, USA \\ *Corresponding author: Sigrid Fry-Revere, Smith College, Georgetown University, USA
}

Submission: 海 March 06, 2018; Published: 阱 March 14, 2018

\section{Opinioin}

I'm a firm believer in the National Organ Transplant Act's (NOTA) [1] prohibition on paid donation. Unfortunately, some efforts to help donors with their lost wages are running afoul of that prohibition. There are many ways in which a donor can get help with lost wages, but too often the entities providing that support do not know what other assistance donors are getting. The end result is that sometimes donors are paid more than once for the same loss. These are preventable violations of NOTA. I personally have witnesses three such violations in the last six months.

NOTA prohibits paying for organs but has an exception that allows donors to be compensated for donation related expenses and losses. Specifically, NOTA prohibits anyone from receiving "valuable consideration" for an organ, but then lists among its exceptions to what constitutes "valuable consideration" "the expenses of travel, housing, and lost wages incurred by the donor of a human organ in connection with the donation of the organ"[1]. The Organ Donation and Recovery Improvement Act of 2004 expanded this exception to include other nonmedical donation related expenses but did not change the general rule about lost wages [2]. Thus, under NOTA, donors can be given paid leave or be compensated for lost wages when they don't have temporary disability benefits. But compensation beyond actual income losses is illegal unless that compensation is for living organ donation related expenses, such as travel, lodging, and other expenses that would not exist but for the organ donation.

The National Living Donor Assistance Center (NLDAC) is the first organization to comes to mind when anyone in the transplant community think of living organ donor assistance programs. Historically, NLDAC helped only with travel related costs for donors and their caregivers and families. NLDAC is now conducting a study where donors are paid lost wages. But, even before the NLDAC study, there were dozens of scenarios where donors' lost income would be covered. The federal government and many states provide their employees with paid leave for organ donation. Some states require private employers beyond a certain size to cover living organ donors' lost wages. Some private employers have decided on their own, without being required to do so by law, to continue paying donors at least part of their wage while they recover from organ donation surgery. And some donors have purchased temporary disability insurance. All these programs, however, have conditions and limitations. For example, the general rule for federal and state living organ donor benefits is that donors must be fulltime government employees for at least one year prior to donating, but in some states, whole classes of employees, even if full-time, are excluded. Also, the length of coverage for such government employee programs can vary from just a few days to several months. For some of the private programs (whether provided by an employer or purchased by the donor), coverage may not start immediately, may be at a rate less than $100 \%$ of the donor's wage or, like with some government employee programs, not last long enough to cover the donors' whole recovery time. So, it can sometimes be hard to determine if donors have coverage, and, even when they do, it can be hard to determine how much of the donor's actual losses will be covered. The question then becomes who is supposed to keep track of this varied and frequently changing landscape of donor benefits and know when it is legal to provide charity grants for expenses usually covered by wages?

When transplant social workers see a living organ donor struggling financially, they make suggestions for how donors can get help and, when necessary, help donors apply for assistance. Often social workers do this expecting that the organization that grants living organ donor assistance will decide based on its own criteria whether the donor qualifies for such assistance. Unfortunately, several of the charities I've spoken to say they rely on transplant social workers to only send them applicants who qualify for the assistance requested. In other words, there are cases, I would venture to say many cases, where no one is checking to see if donors already have at least some paid leave before applying for and / or giving donors grants to cover losses potentially already covered by donors' employers. And, I suspect, even if some social workers and charity administrators are asking donors if they have temporary disability coverage, few are asking the donor's employer to verify a lack of benefits, or if there are benefits, the extent of those benefits. 
This problem is magnified by the fact that sometimes donors think they don't have benefits when they in fact do. I know of six cases where donors applied to the charity where I work for assistance and, when asked to check with their employer about paid leave, the donors were surprised to find that they have coverage. Situations where donors' benefits aren't verified with employers create a risk that donors will be granted over lapping benefits in violation of NOTA's prohibition on paying donors "valuable consideration."

In my work reviewing charity grants, I sometimes suspect overpayment or double dipping. In three cases in the past six months, I've obtained documentation to confirm my suspicion. In each of those cases I notified the transplant social worker and charity in question, informing them of my concern. Only in one instance do I know for certain that policies for verifying lost wages were implemented. I also suspect that some social workers and charity administrators don't understand that helping donors under NOTA is not the same as straight charity.

The prohibition on "valuable consideration" means there are legal limits on what charities are allowed to provide that are totally separate from a charity's own budgetary constraints. Just last week when I asked a donor's social worker if the donor had temporary disability coverage, the social worker responded, "Yes, but it's not enough. She [the donor] is having trouble paying her bills." When I looked into the details of the donor's coverage, I saw she had $100 \%$ coverage for lost wages, starting immediately after surgery, and lasting up to three months. The social workers in her annoyance with my decision not to provide this donor with a grant said, "I was told you guys help donors. I guess I was misinformed." I tried, with no apparent success, to explain that, because of NOTA, charities can only help donors with losses due to their donation, not with unrelated financial problems, and this donor already had all her donation related expenses covered. As a matter of fact, she had already received one charity grant in probable violation of NOTA, and was in the process of applying for another, both to cover losses already covered by her employer.

There is a simple solution. Someone, either the transplant social worker or someone involved in reviewing a charity's applications for assistance, needs to acquire a letter from the donor's employer that specifically states whether the donor has any temporary disability coverage, and if there is such coverage, an explanation of benefits (when the coverage starts and ends and what percentage of wages are covered). I have a sample letter I give donors to pass on to their employers. Also, as a separate inquiry from the documentation requested of employers, every charity should ask the donor for an attestation that identifies all the donor's sources of financial assistance for nonmedical living organ donation related expenses. It is best if this is a separate document than the actual application for assistance, so donors and social workers understand its importance. Such an attestation can help assure that the charity is not covering expenses or losses already covered by someone else.

The attestation I give donors to sign includes a list to help donors identify what types of payments they need to report. For example, "Please let us know if you have received financial assistance to help with your nonmedical living organ donor expenses from any of the following people or types of organizations: your employer; any government entity; your organ recipient or that person's family, friends, or acquaintances; any religious institution or other charity; your own friends, family, or acquaintances; any fundraisers, or other sources. If you have received assistance, please let us know how much and from whom." With this information in hand, charities can calculate what portion of a donor's actual losses still need coverage knowing they've exercised due diligence to prevent the grants they give donors from constituting "valuable consideration" under NOTA. Of course, a donor could lie even on a sworn document, but, requiring an attestation helps prevent accidental double dipping and, if social workers know such a document is part of the grant process, they can alert the charity if they think anything is amiss.

All the charities I know that help living organ donors are struggling to keep up with the demand for assistance. One way to help ease that burden is to eliminate donors who do not legally qualify for assistance from their pool of applicants. I would further argue that it is the transplant community's moral obligation in general to take measures like the ones I've described above to prevent overpayment. We all should want to help ease the financial burdens of living organ donation, but we also should want to protect the integrity of the transplant system and take measures to prevent donors from being compensated more than their actual losses.

\section{References}

1. National Organ Transplant Act of (1984) Pub. L. 98-507, as amended by Pub. L. 100-607 and Pub. L 101-616.

2. The Organ Donation and Recovery Improvement Act of (2004) (PL 108216).
Creative Commons Attribution 4.0 International License

For possible submissions Click Here
Submit Article

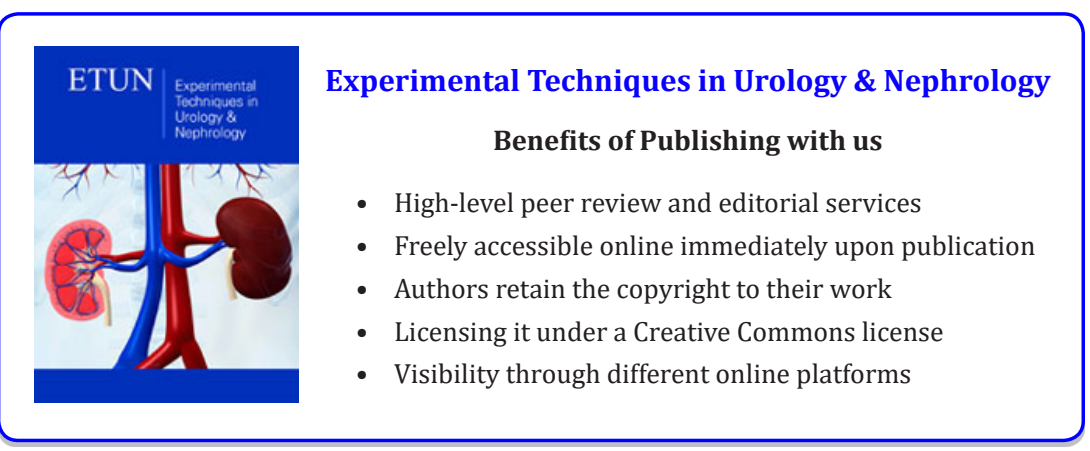

